\title{
An Artificial Intelligence Application in Health Developed on Covid-19 Documents
}

\author{
Murat Aydogan (Corresponding author) \\ Genc Vocational School, Bingol University \\ 12000, Bingol, Turkey \\ E-mail: maydogan@bingol.edu.tr \\ Abdullah Sener \\ Genc Vocational School, Bingol University \\ 12000, Bingol, Turkey \\ E-mail: asener@bingol.edu.tr
}

\begin{abstract}
With the developments in computer science, the concept of artificial intelligence has appeared more frequently in recent years. The concept of artificial intelligence, which is basically defined as computers (machines) thinking like people and making decisions, has become very popular today. Artificial intelligence is used in many fields, especially computer science, education, law, trade, tourism and economy. The health sector is one of these areas. The importance of the applications developed in health sciences has emerged once again, especially during the pandemic process. The development of systems that help reduce the workload of healthcare professionals and make decisions by processing medical data is also an important and real problem that can be solved with artificial intelligence. In this study, natural language processing which is one of the main study subjects of artificial intelligence, has been developed a system that automatically determines the concepts such as disease, medication and treatment on medical data with artificial intelligence by the system. During the experimental studies, it was observed that $91 \%$ accurate estimation was made with the model developed. For this study, a Turkish dataset was created by scanning medical articles and studies related to Covid-19 disease.
\end{abstract}

Keywords: Artificial Intelligence, Turkish natural language processing, Name entity recognition, Covid19

DOI: $10.7176 / \mathrm{JHMN} / 75-08$

\section{Covid-19 Dokümanları Üzerinde Geliştirilen Sağlıkta Bir Yapay Zekâ Uygulaması}

Özet

Bilgisayar bilimlerinde yaşanan gelişmeler ile birlikte son yıllarda yapay zekâ kavramı daha sık karşımıza çıkmaktadır. Temelde, bilgisayarların (makinelerin) insanlar gibi düşünüp karar vermeleri olarak tanımlanan yapay zekâ kavramı günümüzde oldukça popüler hala gelmiştir. Başta bilgisayar bilimleri olmak üzere, eğitim, hukuk, ticaret, turizm, ekonomi olmak üzere birçok alanda yapay zekâdan faydalanılmaktadır. Sağlık sektörü de bu alanlardan biridir. Özellikle içinde bulunduğumuz pandemi sürecinde sağlık bilimlerinde geliştirilen uygulamaların önemi bir kez daha ortaya çıkmışır. Tıbbi verilerin işlenerek sağlık çalışanlarının iş yükünün azaltılması ve karar verilmesine yardımcı sistemlerin geliştirilmesi de yapay zekâ ile çözülebilecek önemli ve gerçek bir problemdir. Bu çalı̧̧mada, yapay zekânın temel çalışma konularından biri olan doğal dil işleme ile tıbbi dokumalar üzerinde hastalık, ilaç ve tedavi gibi kavramların sistem tarafindan yapay zekâ ile otomatik olarak tespit edilen bir sistem geliştirilmiş̧ir. Deneysel çalışmalar sırasında, geliştirilen model ile \%91 oranında doğru tahmin yapıldığ 1 görülmüştür. Bu çalışma için Covid-19 hastalığı ile alakalı makale ve çalışmalar taranarak Türkçe bir veri seti üretilmiştir.

Anahtar Kelimeler: Yapay zeka, Türkçe doğal dil işleme, Varlık ismi tanıma, Covid-19 


\section{Giriş}

Yapay zekâ; düşünme, akıl yürütme, algılama, sonuç çıkarma gibi insana özgü bu özelliklerin analiz edilerek makinelere kazandırılması ve insan gibi düşünebilen, yorumlayabilen, karar verebilen bilgisayar yazılımlarının geliştirilmesidir (Görz, 2002).

Yapay zekânın kullanım alanlarına bakıldığında; Sohbet robotları, yapay zekâ yardımıyla müșteri sorunlarının çözümünde hem daha hızlı hem de daha anlamlı cevaplar verilmesinde kullanılmaktadır. Akıllı asistanlar, veri kümelerindeki önemli bilgilerin çekilmesinde yapay zekâyı kullanarak zamanlamayı iyileştirmektedir. Öneri motorları, kullanıcıların daha önceden deneyimledikleri izleme alışkınlıklarına uygun TV programları önerebilir. Şekil 1'de yapay zekânın kulanım alanlarından bazıları verilmişti. (Bozüyük ve ark.,2005). Şekil 1'de kullanım alanları verilmiştir.

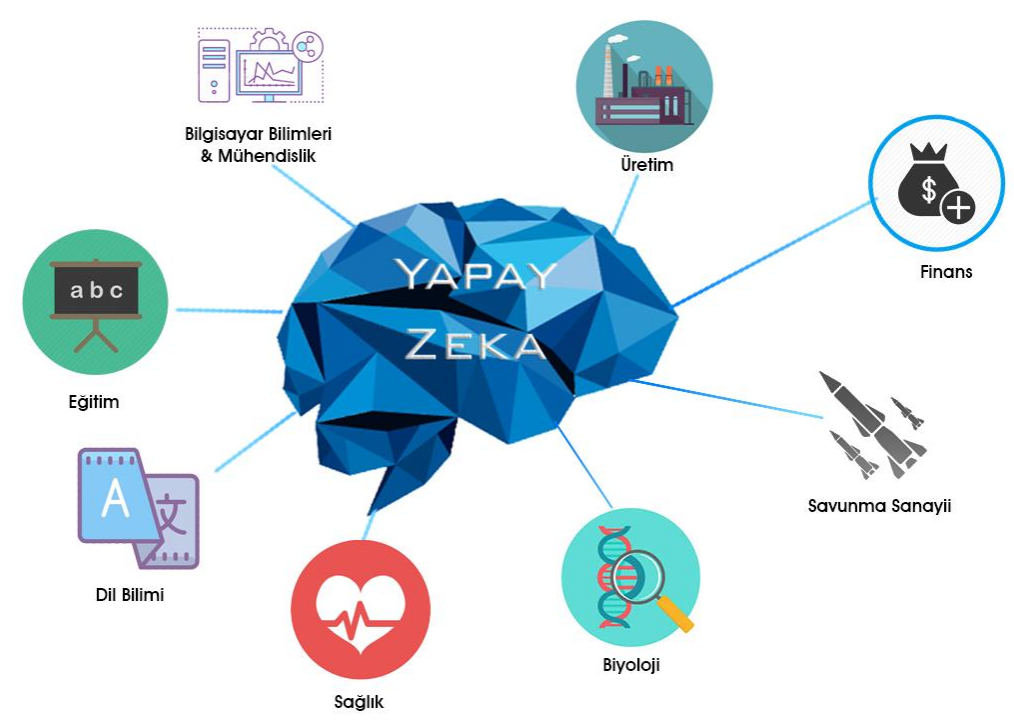

Şekil 1. Yapay zekânın kullanıldığı alanlar

Yapay zekânın kullanıldığı önemli alanlardan biride sağlık alanıdır. Yapay zekâ teknolojileri sağlık hizmetlerinde başta erken teşhis, tanı koyma, karar verme ve tedavi süreci olmak üzere birçok alanda kullanılmaktadır. (Büyükgöze ve Dereli, 2019). Yapay zekâ teknolojileri geliştirilirken kullanılan farklı çalışma alanları vardır.

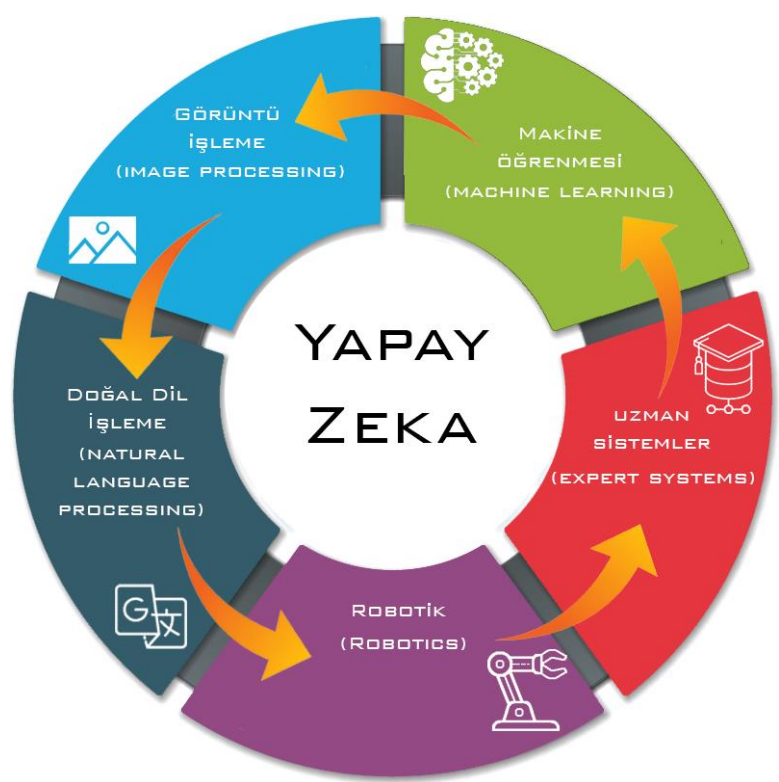

Şekil 2. Yapay zekâ alt dalları 
Yapay zekâ teknolojileri ile Şekil 2'de yer alan alt dalları kullanılarak birçok alanda olduğu gibi sağlık alanında önemli uygulamalar geliştirilmiştir. Bu çalışmalardan bazıları ve kullandıkları yapay zekâ teknolojisi Tablo 1'de görülmektedir (Macdonald,2016), (Johnson, 2018), (Markoff, 2016), (Spencer, 2018), (Webster, 2018), (Lock, 2018).

Tablo1: Yapay zekâ teknolojilerinin sağlık alanında kullanım örnekleri

\begin{tabular}{|c|c|c|c|}
\hline $\begin{array}{l}\text { Kullanım örneği veya } \\
\text { Kullanıcı Grubu }\end{array}$ & Kategori & Uygulama Örnekleri & $\begin{array}{l}\text { Kullanılan Yapay } \\
\text { Zekâ Teknolojisi }\end{array}$ \\
\hline \multirow{4}{*}{ Hastalar ve aileleri } & $\begin{array}{l}\text { *Sağlık İzleme } \\
\text { *Fayda/Risk } \\
\text { Değerlendirme }\end{array}$ & $\begin{array}{l}\text { *Cihazlar ve giyilebilir } \\
\text { cihazlar } \\
\text { *Ak1llı telefonlar ve } \\
\text { tablet uygulamaları, } \\
\text { web siteleri }\end{array}$ & $\begin{array}{l}\text { Makine öğrenmesi } \\
\text { Doğal Dil İşleme }\end{array}$ \\
\hline & Hastalığın Önlenmesi & $\begin{array}{l}\text { *Obezite azalması } \\
\text { *Diyabetin önlenmesi } \\
\text { ve yönetimi } \\
\text { *Duygusal ve zihinsel } \\
\text { sağlık desteği }\end{array}$ & $\begin{array}{l}\text { Doğal Dil İşleme } \\
\text { Makine öğrenmesi }\end{array}$ \\
\hline & $\begin{array}{l}\text { İlaç Tedavisi } \\
\text { Yönetimi }\end{array}$ & İlaç uyumu & Robotik \\
\hline & Rehabilitasyon & $\begin{array}{l}\text { *Rehabilitasyon } \\
\text { uygulamalar1 ve } \\
\text { robotları kullanma }\end{array}$ & Robotik \\
\hline \multirow{3}{*}{ Klinik bakım ekipleri } & $\begin{array}{l}\text { Erken teşhis, tahmin } \\
\text { ve teşhis araçları }\end{array}$ & *Erken kanser tespiti & Makine Öğrenmesi \\
\hline & Cerrahi işlemler & $\begin{array}{l}\text { *Uzaktan kontrollü } \\
\text { robotik cerrahi } \\
\text { *Yapay zekâ destekli } \\
\text { cerrahi yol haritaları }\end{array}$ & $\begin{array}{l}\text { Robotik } \\
\text { Makine Öğrenmesi }\end{array}$ \\
\hline & Hassas tip & $\begin{array}{l}\text { *Kişiselleştirilmiş } \\
\text { kemoterapi tedavisi }\end{array}$ & $\begin{array}{l}\text { Makine Öğrenmesi } \\
\text { Pekiştirmeli Öğrenme }\end{array}$ \\
\hline \multirow[b]{3}{*}{$\begin{array}{l}\text { Halk sağlığı programı } \\
\text { yöneticileri }\end{array}$} & $\begin{array}{l}\text { Risk altındaki } \\
\text { bireylerin } \\
\text { belirlenmesi } \\
\end{array}$ & $\begin{array}{l}\text { *Sosyal medya } \\
\text { kullanarak intihar riski } \\
\text { tanımlama }\end{array}$ & Derin Öğrenme \\
\hline & Nüfus sağllğ1 & *Yaşlı bakımı izleme & Yapay zekâ sensörleri \\
\hline & Nüfus sağlığ1 & $\begin{array}{l}\text { *Hava kirliliği } \\
\text { epidemiyolojisi } \\
* \text { Su mikrop tespiti }\end{array}$ & $\begin{array}{l}\text { Derin Öğrenme } \\
\text { Makine Öğrenmesi }\end{array}$ \\
\hline \multirow[b]{2}{*}{ İşletme yöneticileri } & $\begin{array}{l}\text { Uluslararası Hastalık } \\
\text { Sinıflamas1, }\end{array}$ & $\begin{array}{l}\text { * Tibbi kayıtların geri } \\
\text { ödeme için otomatik } \\
\text { olarak kodlanması }\end{array}$ & $\begin{array}{l}\text { Makine Öğrenmesi } \\
\text { Doğal Dil İşleme }\end{array}$ \\
\hline & Sahtecilik tespiti & $\begin{array}{l}\text { *Sağlık faturalandırma } \\
\text { dolandırıcılığı } \\
\text { *Lisanssız sağlayıcıların } \\
\text { tespiti }\end{array}$ & $\begin{array}{l}\text { Denetimli, denetimsiz } \\
\text { ve hibrit makine } \\
\text { öğrenimi }\end{array}$ \\
\hline \multirow{4}{*}{ Araştırmacılar } & Siber güvenlik & $\begin{array}{l}\text { *Kişisel sağlık } \\
\text { bilgilerinin korunması }\end{array}$ & $\begin{array}{l}\text { Makine Öğrenmesi } \\
\text { Doğal Dil İşleme }\end{array}$ \\
\hline & Doktor yönetimi & $\begin{array}{l}\text { *Hekim yeterliliğinin } \\
\text { değerlendirilmesi }\end{array}$ & $\begin{array}{l}\text { Makine Öğrenmesi } \\
\text { Doğal Dil İşleme }\end{array}$ \\
\hline & Hastalık tahmini & $\begin{array}{l}\text { *Yumurtalık kanserinin } \\
\text { tahmini }\end{array}$ & Sinir Ağları \\
\hline & Keşif & * İlaç keşfi ve tasarımı & Makine Öğrenmesi \\
\hline
\end{tabular}

\section{Materyal ve Metot}

$\mathrm{Bu}$ çalışmada metodoloji olarak Şekil 3'te görünen yapı uygulanmıştır. İlk olarak Google Scholar platformunda yer alan sağlık alanındaki akademik çalışmalar taranarak veriseti olarak kullanılmak üzere bir doküman (derlem) oluşturulmuştur. Daha sonra üretilen bu veriseti üzerinde ön işleme çalışmaları yapılarak veriler işlenebilir hale getirilmiştir. Bir sonraki adımda ise verilerin etiketlenme işlemi yapılmış 
ve veriler eğitim verisi - test verisi olarak ayrılmıştır. Eğitim modeli oluşturularak eğitim süreci işletilmiş daha sonra test süreci uygulanmıştır.

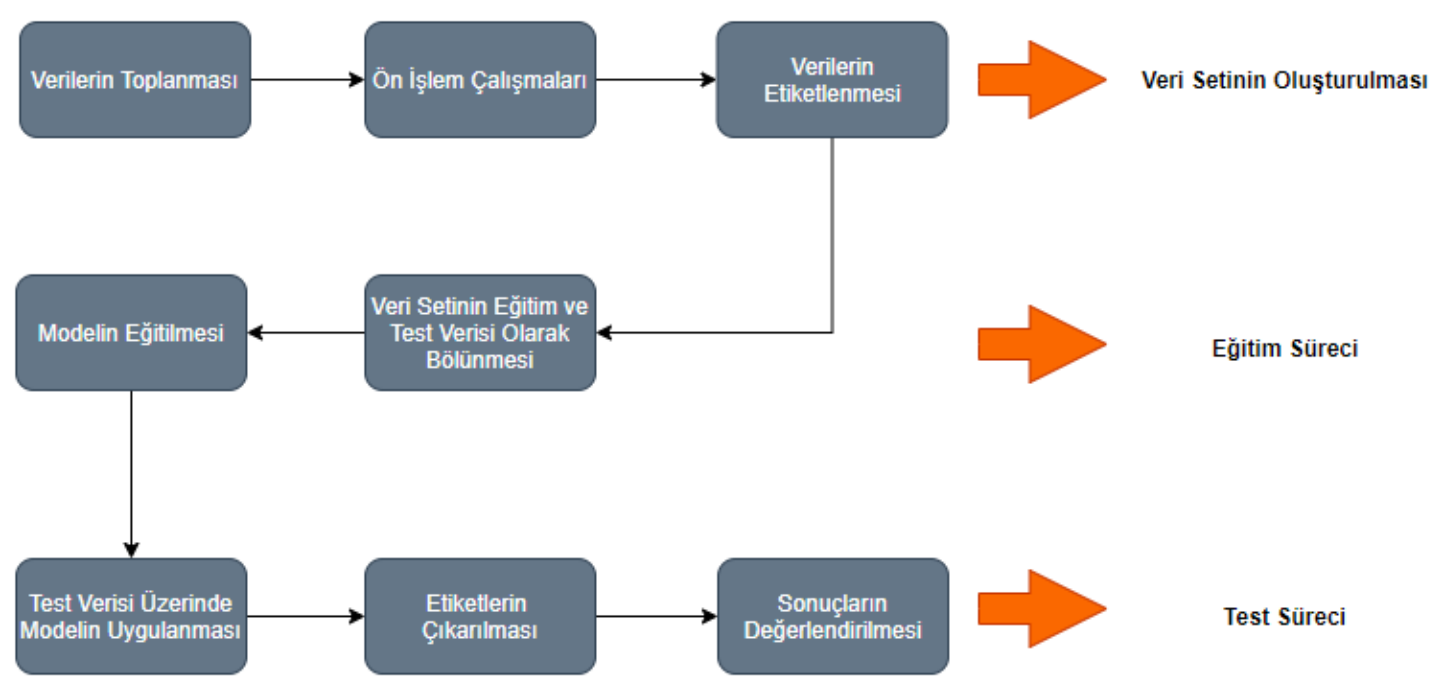

Şekil 3. Geliştirilen modelin genel yapısı

\subsection{Materyal}

Sağlık alanındaki terimleri içeren Türkçe bir veri seti literatür de yer almamaktadır. Bu nedenle çalışmanın amacı doğrultusunda Türkçe bir veri seti üretilmiş ve bundan sonraki çalışmalara katkı sağlanması hedeflenmiştir.

Verilerin Toplanması- Bu çalışmada kullanılmak üzere Google Scholar platformunda yer alan Türkçe 100 adet sağlık alanındaki akademik çalışma ve bazı web sayfalarının içerikleri çekilerek bir derlem oluşturulmuştur.

Ön İşlem Aşamast- Oluşturulan veri seti üzerinde ön işlem çalışmaları yapılarak veriler işlenebilir hale getirilmiştir. Bu çalışmalardan ilki metinlerin tamamının küçük harflere çevrilmesi, cümle sonundaki noktalar referans alınarak metinlerin cümlelere daha sonra cümle içindeki boşluklara göre de cümlelerin kelimelere dönüştürülmesidir. Son olarak noktalama işaretleri temizlenmiş, normalizasyon işlemleri uygulanmıştır.

Verilerin Etiketlenmesi- Ön işlem aşamasından sonra kelimelere dönüştürülmüş verilerin etiketlenme işlemi yapılmıştır. Etiketleme için kullanılan varlık isimleri olarak şunlar tercih edilmiştir. Kişi, Kurum, Yer, Hastalık, Belirti, Tedavi, Anatomik Yapı Adı (AYA). Varlık isimlerinin tespit edilmesinde ve verilerin etiketlenmesinde enfeksiyon hastalıkları doktoru bir uzmandan destek alınmıştır.

\subsection{Metot}

\subsubsection{Doğal Dil İşleme}

Doğal dil işleme yapay zekânın en fazla çalışılan dolayısıyla da en önemli alt dallarından biridir. Doğal dil işleme en basit tanımla Türkçe, İngilizce, Almanca gibi doğal dillerin işlenmesi ve üzerinde çalışmalar yapılması ile ilgili bir bilim dalıdır (Kocatekin ve Ünay, 2013). Doğal dil işlemenin temel görevleri arasında bir metnin bir dilden başka bir dile çevrilmesi, bir metnin ait olduğu kategoriye göre sınıflandırılması, soru-cevap sistemleri ve akıllı asistanların geliştirilmesi gibi belli başlı konular gösterilebilir (Küçük ve Arıcı, 2018). Kısaca bir metin üzerinde yapılabilecek her türlü araştırma ve geliştirme uygulamaları doğal dil işlemenin çalışma alanına girmektedir. Bu nedenle günümüzde oldukça popüler ve önemli bir çalışma alanıdır bu durumun üretilen veri miktarlarının artmasıyla birlikte gelecekte daha da önem kazanacağ 1 tahmin edilmektedir.

2.2.2 Varlık İsmi Tanıma

Varlık ismi tanıma, yapay zekânın popüler alt başlıklarından biri olan doğal dil işlemenin önemli bir çalışma konusudur. Bu problem ile ilgili çeşitli alanlara yönelik çalışmalar yapılmıştır. Ancak sağlık alanı ile alakalı çalışmalar olsa da bunların sayısı yeterli düzeyde değildir. Ayrıca yapılan çalışmalar incelendiğinde başta İngilizce dili olmak üzere farklı dillerde uygulamalar bulunmakta iken Türkçe diline ait çalışmaların sayısı çok sınırlıdır. Bu nedenle bu çalışmanın dili de Türkçe olarak seçilmiş ve Türkçe bir veri seti üretilmiştir (Eken,2015).

$\mathrm{Bu}$ çalışmada, varlık isimlerinin etiketlenmesi işlemi tamamlandıktan sonra geliştirilen model ile bu varlık isimlerinin model tarafından yapay zekâ ile tespit edilmesi hedeflenmiştir. Etiketleme işlemi

61 | P a g e 
aşamasında şöyle bir format kullanılmıştır. Tablo 2'de etiketleme örneği görülmektedir. $\mathrm{B}=>$ Bir varlık ismi başladı, $\mathrm{I}=>$ Varlık ismi devam ediyor (içinde), $\mathrm{O}=>$ Varlık isminin dişında

Tablo 2. Varlık isimlerinin etiketlenme yönteminin örneği

\begin{tabular}{|c|c|c|c|c|c|c|c|c|c|c|}
\hline \multirow{2}{*}{ Örnek-1 } & Kelime & kalp & \multicolumn{2}{|c|}{ hastas1 } & olabilir & bronşit & iltihab1 & var & antibiyotik & tedavisi \\
\hline & Etiket & B-AYA & $\mathrm{C}$ & & $\mathrm{O}$ & B-Hastalık & $\mathrm{O}$ & $\mathrm{O}$ & B-Tedavi & $\mathrm{O}$ \\
\hline \multirow{2}{*}{ Örnek-2 } & Kelime & \multicolumn{2}{|c|}{ hemodiyaliz } & \multicolumn{2}{|c|}{ kronik } & böbrek & yetmezliğ & \multicolumn{2}{|c|}{ hastalarında } & uygulanır \\
\hline & \begin{tabular}{|l|} 
Etiket \\
\end{tabular} & B-Teda & & & astalık & I- Hastalık & I- Hastalı & & $\mathrm{O}$ & $\mathrm{O}$ \\
\hline
\end{tabular}

Etiketleme işlemi sonrasında oluşturulan veri setinde yer alan hastalık, tedavi ve diğer etiketlerine sahip varlık isimlerinden bazıları tabloda verilmiştir. Daha öncede değinildiği üzere $B$ bir varlık isminin başladığını, $I$ geçerli varlık isminin devam ettiğini son olarak $O$ ise varlık isminin dışında olduğunu yani herhangi bir varlık ismine ait olmadığını temsil etmektedir. Tablo 3'te örnek etiketler görülmektedir.

Tablo 3. Etiketlenmiş veri örnekleri

\begin{tabular}{|c|l|}
\hline B-Hastalık & kanser boğmaca frengi bronşit ülser dizanteri egzama diyabet guatr hepatit...... \\
\hline I-Hastalık & iltihap ağrı kanama yara bulantı felci şişliği çarpması yanığı zorluğu darlığı ...... \\
\hline B-Tedavi & kemoterapi antibiyotik mezoterapi osteopati akupunktur ....... \\
\hline I-Tedavi & uygulamalar terapi sonda nakli küçültmek baypas protez hortum(tüp)...... \\
\hline O & modern hizmet ülkemiz çok ve yöntem sistem ayrıca insan durum ....... \\
\hline
\end{tabular}

\subsubsection{Kelime Vektörleri}

Doğal dil işleme problemlerinde bir kelimenin gösterim biçimi bir başka deyişle bilgisayarın o kelimeyi nasıl anlayacağı bu problemin en kritik noktasıdır. Bu gösterim şeklinin geleneksel ve modern olarak sınıflandırılabilecek çeşitleri vardır (Goldberg ve Levy, 2014). Günümüzde kullanılan en popüler yöntem Google yapay zekâ araştırmaları ekibi tarafindan geliştirilen, kelimelerin vektör biçiminde sayısal ifadelerle temsil edildiği Word2Vec yöntemidir (Rong, 2014). Bu yönteme göre her bir kelime uzayda vektörlerle doğru bir şekilde sembolize edilirse, bir vektöre dolayısıyla vektörün temsil ettiği kelimeye en yakın vektör en yakın anlamlı kelime olarak düşünülebilir. İki vektör arasında ki yakınlık kosinüs benzerliği ile tespit edilebilmektedir (Aydoğan ve Karc1, 2019).

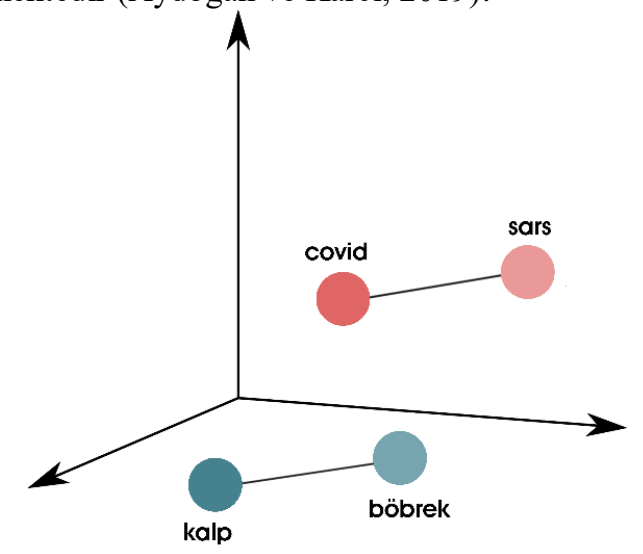

Şekil 4. İlişkili kelimelerin düzlem üzerindeki gösterimi

Şekil 4'te vektörel forma dönüştürülmüş yakın anlamlı kelimelerin tespit edildiği görülmektedir. Bu çalışmada da yakın anlamlı kelimelerin belirlenebilmesi için oluşturulmuş Türkçe veri seti üzerinde Word2Vec metodu kullanılarak çalışmalar yapılmıştır.

\subsubsection{Yapay Sinir Ağları}

Yapay sinir ağları, günümüzde kullanılan birçok yapay zekâ yaklaşımının temelini oluşturmaktadır. Esasen yapay sinir ağlarında, kendi kendine öğrenebilme ve değerlendirme yapabilme özellikleri ile insan beyninin modellenmesi hedeflenmiştir. Daha öncede değinildiği üzere bu durumda yapay zekâ denilen yaklaşımın temelidir. Çünkü makinelerin de insanlar gibi eğitilebilmesi, öğrenebilmesi ve çıkarımlar yapabilmesi amaçlanmıştır (Öztürk ve Şahin, 2018). Şekil 5’te bir yapay sinir ağının yapısı görülmektedir. 


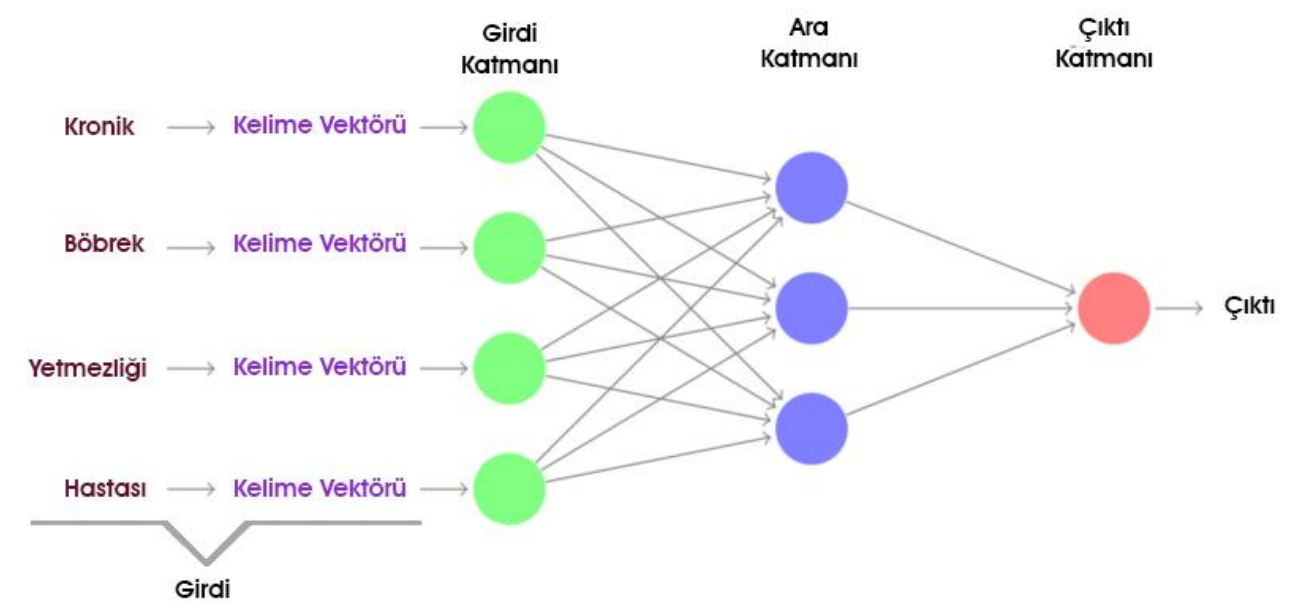

Şekil 5. Yapay sinir ağı yapısı

\section{Deneysel Çalışmalar}

$\mathrm{Bu}$ çalışma için üretilen Türkçe veri seti eğitim ve test verisi olarak iki kısma bölünmüş eğitim verisi üzerinde geliştirilen modelin eğitim işlemi yapılmış, test verisi üzerinde ise modelin eğitimi tamamlandıktan sonra hiç görmediği veriler üzerinde tahminler yapması sağlanmıştır. Üretilen veri setinin \%80'lik kısmı eğitim verisi \%20'lik kısmı ise test verisi olarak bölünmüştür. Tablo 4 'te eğitim ve test verisinde yer alan toplam kelime sayısı ayrıca hastalık, belirti, tedavi, anatomik yapı adı (AYA) gibi kategorilerden yer alan kelime sayıları da yer almaktadır.

Tablo 4. Kategorilere göre veri setinde bulunan kelime sayıları

\begin{tabular}{|l|l|c|c|c|c|c|c|c|c|}
\hline & & $\begin{array}{c}\text { Kelime } \\
\text { Sayısı }\end{array}$ & Kişi İsmi & Kurum & Yer & Hastalı & Belirti & Tedavi & AYA \\
\hline Veri Seti & Eğitim & 742400 & 10811 & 951 & 3830 & 16718 & 18265 & 9534 & 30269 \\
\hline & Test & 185600 & 3099 & 118 & 500 & 11921 & 6331 & 1056 & 5067 \\
\cline { 2 - 10 } & & 928000 & & & & & & & \\
\hline
\end{tabular}

Üretilen Türkçe veri seti üzerinde Word2Vec yöntemi kullanılarak kelime vektörleri oluşturulmuştur. Deneysel çalışmalar sırasında bu vektörlerin dolayısıyla temsil ettikleri kelimelerin birbirleri ile olan anlamsal ilişkileri incelenmiştir. Örneğin "covid" kelimesi ile yakın anlamlı kelimeler listelenmek istendiğinde virüs, maske, sars, sosyal mesafe gibi kelimelerin tespit edildiği görülmüștür. Dilimizi bilmeyen bir sistem belli bir kelime sorgulatıldığında başarılı bir şekilde o kelime ile benzer kelimeleri yakalamıştır. Bu durum Şekil 6'da ki gibi görselleştirilmiştir.

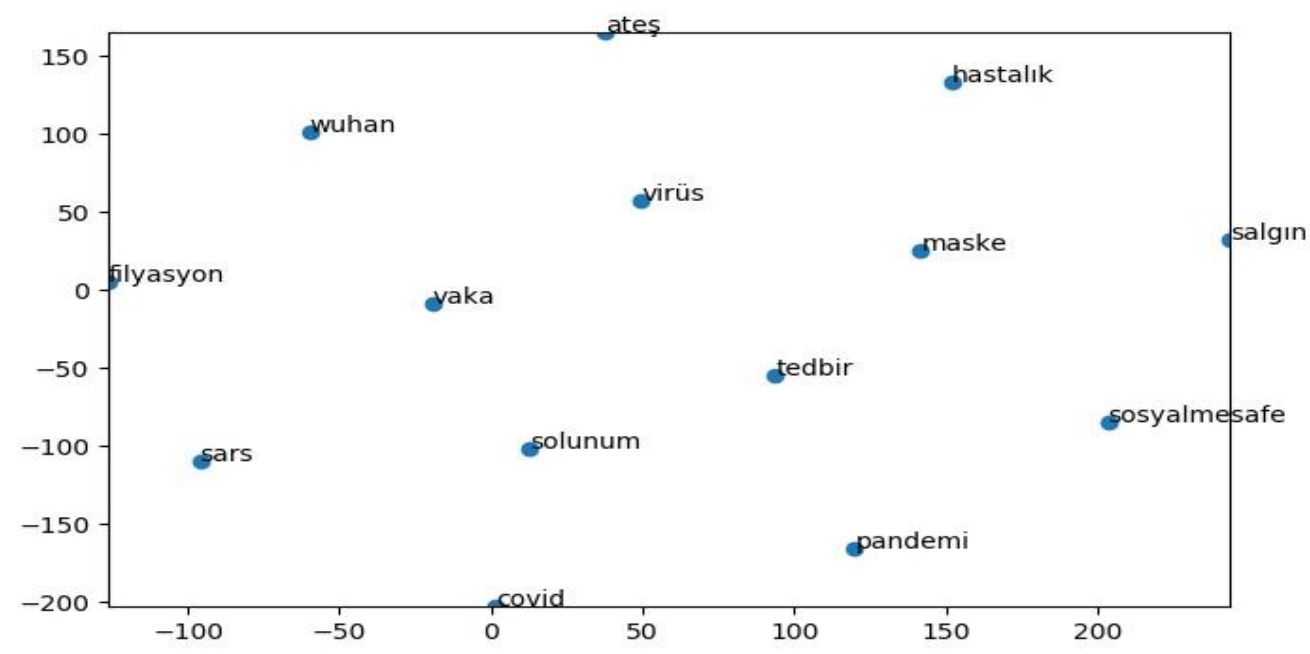

Şekil 6. Covid kelimesi ile ilişkili kelimelerin 2 boyutlu düzlemde gösterimi 
Yapay zekâ teknolojilerinin sağlık alanında kullanımı ile birlikte geliştirilebilecek uygulamalar ile sağlık çalışanları üzerinde ki iş yükünün azaltılması daha kısa sürede daha çok bilgiye erişimin sağlanarak günümüz teknolojilerinin bu tür kritik alanlarda daha fazla yer alması hedeflenmektedir. Bu kapsamda covid-19 hastalığı ile alakalı akademik çalışmalardan üretilmiş kelime vektörleri ile semptom ve tedbir kelimeleri sorgulatıldığında elde edilen sonuçlar heyecan vericidir. Örneğin semptom kelimesi ile elde edilen sonuçlar incelendiğinde en yüksek skor ile elde edilen ilk kelimeler ateş, öksürük, ishal gibi sağlık bakanlığı tarafindan covid-19 hastalığının en belirgin belirtileri olarak kabul edilen semptomlar yakalanmıştır. Şekil 7'de yer alan bir diğer örnekte ise tedbir kelimesi sorgulatılmış yine en yakın ilişkili 10 kelime skor değerlerine göre listelendiğinde maske, sosyal mesafe gibi kelimeler elde edilmiştir. Pandemi sürecinin en yaygın sloganlarından olan evdekal ifadesinin de burada yakalanmış olması dikkat çekicidir. Bu durumda yapay zekânın gücünü bir kez daha ortaya koymaktadır.

\begin{tabular}{|l|l|}
\hline \multicolumn{1}{|c|}{ vector('semptom”) } & \multicolumn{1}{c|}{ vector('“tedbir”) } \\
\hline [('ateş', 0.7206), & [('önlem', 0.7751), \\
('öksürük', 0.6463), & ('maske', 0.7654), \\
('ishal', 0.6445), & ('sosyalmesafe', 0.7424), \\
('ağri', 0.6126), & ('temas', 0.7126), \\
('boğaz', 0.5989), & ('vaka', 0.6989), \\
('göğüs', 0.5809), & ('mesafe', 0.6816), \\
('solunum', 0.5762), & ('evdekal', 0.6629), \\
('kuru', 0.5708), & ('salgin', 0.6073), \\
('belirti', 0.5695), & ('pandemi', 0.5561), \\
('covid', 0.5689)] & ('yasak', 0.5430)] \\
\hline
\end{tabular}

Şekil 7. İlişkili kelimelerin listesi

Bu çalışmanın temel amacı ise üretilen Türkçe veri seti üzerinde etiketlenen varlık isimlerinin geliştirilen model ile eğitilmesinin ardından sistemin görmediği verileri tahmin edip varlık isimlerini otomatik olarak çıkarabilmesidir. Örneğin Şekil 8'de görülen program çıktısında eğitim işlemi sonrasında test verisi olarak sisteme verilen verilerden varlık ismi olarak tahmin edilen kelimeler model tarafindan çıkarılmıştır. Öksürük, ateş gibi kelimeler belirti olarak tanımlanırken, kanser, bronşit ve diyabet gibi kelimelerin hastalık olduğu doğru olarak tahmin edilmiştir. Bu uygulamanın özellikle covid-19 gibi yeni hastalıklar ile alakalı yapılabilecek akademik taramalarda büyük kolaylık sağlayacağı düşünülmektedir.

Kanser olmuș, kalp hastası da olabilir. Karaciğer tedavisi için hastaneye yattım. Soğuk algınlığı, diș çürüğü, böbrek ağrısı, bronșit ve diyabet var. Antibiyotik tedavisi uygulanmaktadır. Öksürük ve yüksek ateș nedeniyle derhal müdahale

Renk Kodları: hastalık, anatomik yapı adı, tedavi, belirti

Şekil 8. Uygulamanın ekran çıktısı

Modelin performansının değerlendirilmesinde ise yapay zekâ çalışmalarında en sık kullanılan precision, recall ve f-score ölçütleri kullanılmış ve bu değerler aşağıdaki 1,2 ve 3 numaralı formüller ile hesaplanmıştır.

$$
\begin{aligned}
& \text { Precision }=\frac{\text { Modelin Doğru Tahminleri }}{\text { Modelin Tüm Tahminleri }} \\
& \text { Recall }=\frac{\text { Modelin Doğru Tahminleri }}{\text { Modelin Bilmesi Gereken Tüm Varllk İsimleri }} \\
& \mathrm{F}-\text { Score }=\frac{2 * \text { Precision } * \text { Recall }}{\text { Precision+Recall }}
\end{aligned}
$$


Tablo 5. Geliştirilen modelin başarım oranları

\begin{tabular}{|l|l|l|l|}
\hline & Precision $\mathbf{( \% )}$ & Recall $\mathbf{( \% )}$ & F-Score $(\%)$ \\
\hline B-Kişi & 82.32 & 72.92 & 77.33 \\
\hline B-Kişi & 78.40 & 74.80 & 76.66 \\
\hline I-Kurum & 82.61 & 71.03 & 76.38 \\
\hline B-Yer & 85.77 & 74.65 & 79.82 \\
\hline I-Yer & 78.90 & 75.20 & 77.00 \\
\hline B-Hastalık & 71.11 & 69.88 & 70.49 \\
\hline I-Hastalık & 87.31 & 62.63 & 67.03 \\
\hline B-Belirti & 83.25 & 69.20 & 77.21 \\
\hline I-Belirti & 86.01 & 76.75 & 79.87 \\
\hline B-Tedavi & 86.55 & 84.25 & 85.12 \\
\hline I-Tedavi & 86.88 & 73.18 & 79.31 \\
\hline B-AYA & 85.33 & 83.64 & 85.23 \\
\hline I-AYA & 77.50 & 86.56 & 85.94 \\
\hline O & 95.86 & 75.80 & 76.67 \\
\hline \multicolumn{4}{|l|}{} \\
\hline
\end{tabular}

Tablo 5'te veri setinde etiketlenen varlık isimlerinin başladığ 1 (B) ve devam ettiği (I) durumları farklı etiketler halinde precision, Recall ve f-score ölçütlerine göre elde ettiği başarım oranları görülmektedir. Bir başka deyişle modelin eğitim süreci sırasında hiç görmediği test verisi üzerinde yaptığı tahminlerin sonuçlarıdır denilebilir. Örneğin model herhangi bir varlık ismi olmayan ve $\mathrm{O}$ etiketi ile temsil edilen verilerin yaklaşık \%95'ini doğru olarak tahmin etmiştir. Hastalık isimlerinin başladığı B-Hastalık etiketlerde precision değeri \%72 iken, devamını temsil eden I-Hastalık etiketinde ise bu değer \%87 olmuştur. Yani model hastalık isimlerinin devam ettiği etiketi tahmin etmede, başladığı etiketi tahmin etmeye göre daha başarılı olmuştur.

Deneysel çalışmaların tümü Python 3 programlama dili ve Anaconda ortamı ayrıca Microsoft Windows Server 2012 R2 işletim sistemi ile Intel Xeon E5-2630 2.20 CPU ve 64 GB bellek kullanılarak geliştirilmiştir.

\section{Sonuçlar}

Yapay zekâ teknolojileri başta bilgisayar bilimleri ve mühendislik alanında olmak üzere birçok alanda kullanılmakta ve oldukça başarılı performanslar sağlamaktadır. Sağlık alanıda özellikle son yıllarda yapay zekânın kullanımı ile birlikte önemli gelişmelerin yaşandığı bir alan haline gelmişstir. Toplum için hayati bir öneme sahip olan sağlık alanında yapılan tüm araştırmalar başta sağlık çalışanlarının iş yükünü azaltmayı, karar verebilmelerini kolaylaştırmayı hedeflemekte olduğu için oldukça kıymetli olarak kabul edilmektedir. Bu nedenle yapay zekânın önemli alt alanlarından biri olan doğal dil işleme teknikleri ile yapay zekâ temelli bir uygulama geliştirilmiştir.

Çalışmada kullanılmak üzere Google Scholar platformundan sağlık alanına yönelik Türkçe akademik makaleler ve çeşitli web sayfalarından toplanan Türkçe içerikler ile literatürde bulunmayan özgün ve yeni Türkçe bir veri seti üretilmiştir. Bu veri seti üzerinde yapılan çalışmalar neticesinde geliştirilen model ile sisteme yüklenen metinlerde hastalık, tedavi, belirti gibi etiketlerin otomatik olarak tanımlanması hedeflenmiştir. Bu durumun özellikle covid-19 gibi yeni hastalıklar hakkında bilgi toplanması, literatür taranması, araştırma yapılması safhasında büyük kolaylık sağlayacağı düşünülmektedir.

Yapılan deneysel çalışmalar sonrasında, metinler içerisinden kişi, kurum, yer, hastalık, belirti ve tedavi gibi varlık isimlerinin \%91 başarım oranında doğru olarak çıkarıldığ 1 görülmüş ve bu performans precision, recall ve f-score gibi ölçütler ile desteklenmiştir. Ayrıca bu çalışma kapsamında üretilen Türkçe veri setinin, doğal dil işleme ve yapay zekâ çalışmalarına katkı sağlaması amacıyla araştırmacılar ile paylaşılması planlanmaktadır.

\section{Referanslar}

Aydoğan, M, Karci, A. (2019). Kelime Temsil Yöntemleri ile Kelime Benzerliklerinin İncelenmesi. Çukurova Üniversitesi Mühendislik-Mimarlık Fakültesi Dergisi, 34 (2), 181-196. DOI: 10.21605/cukurovaummfd.609119 
Bozüyük, T., Yağci, C., Gökçe, İ., \& Görkem, A. K. A. R. (2005). Yapay Zeka Teknolojilerinin Endüstrideki Uygulamalari.

Büyükgöze, S., \& Dereli, E. (2019). Dijital Sağlık Uygulamalarında Yapay Zeka. VI. Uluslararası Bilimsel ve Mesleki Çalışmalar Kongresi-Fen ve Sağllk, 07-10.

Eken, B. (2015). Kısa Metinlerde Varlık Ismi Tanıma (Doctoral dissertation, Fen Bilimleri Enstitüsü).

Goldberg, Y., \& Levy, O. (2014). word2vec Explained: deriving Mikolov et al.'s negative-sampling

Görz, G., \& Nebel, B. (2002). Yapay zeka. İstanbul: İnkılap Kitapevi.

Johnson, Khari; (2018), "Baidu Researcher's breast cancer dedection algorithm outperforms human pathologists", Venture Beat, (18 Haziran 2018), https://venturebeat.com/2018/06/18/baiduresearchs-breast-cancer-detection-algorithm-outperforms-human-pathologists/. (Erişim Tarihi: 05.06.2020)

Kocatekin, T., \& Ünay, D. (2013, April). Text mining in radiology reports. In 2013 21st Signal Processing and Communications Applications Conference (SIU) (pp. 1-4). IEEE.

Küçük, D., \& Arici, N. (2018). Doğal Dil İşlemede Derin Öğrenme Uygulamalari Üzerine Bir Literatür Çalişmasi. Uluslararası Yönetim Bilişim Sistemleri Ve Bilgisayar Bilimleri Dergisi, 2(2), 76-86.

Linn, Allison; "How Microsoft computer scientists and researchers are working to 'solve' cancer", Microsoft, https://news.microsoft. com/stories/computingcancer/. (Erişim Tarihi: 05.06.2020)

Lock, Stan; (2018), "Danish startup Corti uses AI to save people from cardiac arrest “, Business Insider Nordic, (30 Nisan 2018), https://nordic.businessinsider.com/danish-speech-recognition-aicorti-saves-lives-by-detecting-cardiac-arrest-in-real-time--/. (Erişim Tarihi: 05.06.2020)

Macdonald, Fiona; (2016), “AI Can Analyse Mammogram Results 30 Times Faster Than Doctors, And With 99\% Accuracy", Science Alert, (19 Eylül 2016), https://www.sciencealert.com/aianalyses-mammograms-30-times-faster-and-20-more-accurately-than-doctors. (Erişim Tarihi: 05.06.2020)

Markoff, John; (2016), "Microsoft Finds Cancer Clues in Search Queries", New York Times, (7 Temmuz 2016), https://www.nytimes.com/2016/06/08/technology/online-searches-can-identifycancer-victims-study-finds.html. (Erişim Tarihi: 05.06.2020)

Öztürk, K., \& Şahin, M. E. Yapay Sinir Ağları ve Yapay Zekâ’ya Genel Bir Bakış. Takvim-i Vekayi, 6(2), 25-36, (2018).

Rong, X. (2014). word2vec parameter learning explained. arXiv preprint arXiv:1411.2738.ordembedding method. arXiv preprint arXiv: 1402.3722.

Spencer, Geoff; (2018), "AI and preventative healthcare: Diagnosis in the blink of an eye", Microsoft Asia News Center, (17 Eylül 2018), https://news.microsoft.com/apac/features/ai-andpreventative-healthcare-diagnosis-in-the-blink-of-an-eye/. (Erişim Tarihi: 05.06.2020)

Webster, William; (2018), "Smartphones and Selfies sourcing AI Healthcare Diagnostics", Avoncourt, (30 Kasım 2018), http://avoncourt.de/smartphones-and-selfies-sourcing-aihealthcare-diagnostics/. (Erişim Tarihi: 05.06.2020) 